\title{
Arterial stiffness in patients with localized and generalized severe chronic periodontitis: A preliminary study
}

\author{
Erry Mochamad Arief, Ho Ting Khee, Asia Rehman, Akram Hassan, \\ Mohd. Fadhli Khamis
}

School of Dental Sciences, Universiti Sains Malaysia

\begin{abstract}
A relationship between periodontal disease and cardiovascular disease (CVD) has been reported in several studies. This association was explained based on chronic systemic inflammatory response which may lead to arterial stiffness in chronic periodontitis (CP). To compare arterial stiffness as carotidfemoral pulse wave velocity (PWV) between patients with localized severe CP (LSCP) and generalized severe CP (GSCP). Five patients with LSCP and 12 patients with GSCP were recruited in a cross sectional study. Subjects were excluded if they had systemic diseases other than CP. Diagnosis of LSCP and GSCP was made based on probing depth and radiographic bone loss. Carotid femoral PWV was measured using the Complior ${ }^{\circledR}$ machine. Data was analyzed using SPSS. Carotid femoral PWV was higher among patients with GSCP as compared to those with LSCP although the difference did not reach significant level. Median (interquartile range) PWV was $7.5(1.50)$ and $7.0(1.03) \mathrm{m} / \mathrm{sec}$ respectively in patients with GSCP and LSCP $(p=0.224)$. Among patients with CP, aorta is stiffer in GSCP than in LSCP.
\end{abstract}

Key words: Arterial stiffness, chronic periodontitis, cardiovascular disease, pulse wave velocity

\section{INTRODUCTION}

Cardiovascular disease is the second cause of mortality among Malaysians and world population according to the Malaysian Health Report and The World Health Report 2008..$^{1,2}$ The relationship between CVD and oral health has attracted the interest among researchers for over two and a half decades. Consequently periodontal disease has been suggested to be important risk factor for $\mathrm{CVD}^{3}$ apart from diabetes, hypertension, and smoking, abnormal serum lipids and age. ${ }^{4}$ Several studies indicated an association between periodontal disease and CVD. Mattila et al. ${ }^{5}$ were the first to show the statistical association between poor dental health and myocardial infarction in a case-control study even after the adjustment for classical risk factors was made. An approximately $25 \%$ increase in risk for CVD was observed in subjects with periodontal disease in a longitudinal study in $1993 .{ }^{6}$ The relative risk for ischemic stroke was 2.11 for subjects with periodontitis according to the First National Health and Nutrition Examination Survey and its follow-up study. ${ }^{7}$ Similarly, a positive association between CVD, mean attachment level loss and mean pocket depth with odds ratio 3.17 and 8.64 respectively was reported. ${ }^{8}$

Endothelial dysfunction has been showed to be an early event in developing atherosclerosis.

Correspondence author: Erry Mochamad Arief, School of Dental Sciences, Universiti Sains Malaysia, 16150 Kubang Kerian, Kelantan, Malaysia 
suggesting a mechanism for association between periodontal disease and CVD. The evident become stronger after researchers shown an improvement in endothelial dysfunction in subjects with periodontal disease and poor oral status and with a reduction in $\mathrm{C}$ reactive protein (CRP), after periodontal treatment. ${ }^{10,11}$ Endothelial dysfunction is associated with arterial stiffness which may be measured by PWV, a simple non invasive and easily reproducible technique. ${ }^{12} \mathrm{PWV}$ is strongly associated with atherosclerosis at various sites in the vascular tree..$^{13}$ Although many studies showed an association between periodontal disease and CVD, the relationship between the severity of the periodontal disease and arterial stiffness, an indicator of CVD was not reported. The objective of this study was to compare the carotid-femoral PWV between patients with localized and GSCP and to determine its correlation with plaque index and Bleeding on probing (BOP) in subjects with severe $\mathrm{CP}$.

\section{MATERIALS AND METHODS}

We conducted a cross sectional comparative study and recruited 5 subjects with LSCP and 12 subjects with GSCP patients from the outpatient dental clinics of Hospital Universiti Sains Malaysia (HUSM) who visited the clinic during study period. Only subjects with newly diagnosed of severe CP and who had not received any periodontal treatment in past 6 months of the study were included. Exclusion criteria were the presence of systemic disease (e.g., diabetes mellitus or cardiovascular, kidney, liver, or lung disease), a history or the presence of any other acute or chronic infections, as assessed on clinical examination and routine laboratory testing, pregnant women and systemic antibiotic treatment within the previous 3 months, hormone replacement therapy or any other, regular medication. All patients gave written informed consent. The study was approved by the School of Medical Sciences Universiti Sains Malaysia Ethics Committee.

A complete periodontal examination was performed and an orthopantomograph taken. The examination included the Probing Depth (PD) and the recession of the gingival margin relative to the cementoenamel junction at six sites per tooth. The presence or absence of supragingival dental plaque and gingival bleeding on probing was also recorded. The whole mouth PD was measured by the University of Michigan $O$ probe (Medesy, Italy), with William's markings. Full mouth Plaque index (the number of sites with detectable supragingival dental plaque divided by the total number of sites per mouth, multiplied by 100$)^{14}$, and full mouth BOP (the number of sites with gingival bleeding on probing divided by the total number of sites per mouth, multiplied by 100$)^{15}$, were carried out.

Based on the assessment of all individual teeth in the mouth by single examiner, periodontal status of the subjects was group into two categories: LSCP and GSCP. Severity of CP based on probing pocket depths of $>6 \mathrm{~mm}$ and marginal alveolar bone loss of $>30 \%$. Extension of CP based on localized $<30 \%$, generalized $>30 \%$ involved. ${ }^{16,17}$

Following the periodontal assessment, measurement of PWV was carried out in The Clinical Trial Unit (CTU) of Hospital Universiti Sains Malaysia (HUSM). Subjects reported to CTU for measurement of PWV after overnight fast.

Carotid femoral PWV was then measured noninvasively using an automatic Complior ${ }^{\circledR}$ (Colson, France) machine. ${ }^{12}$ The machine allows pulse wave recording and automatic calculation of PWV with two transducers, one positioned at the base of the neck for the common carotid and the other over the femoral pulse points. An average of ten such recordings was obtained and recorded. All the measurements were performed on the right side of the patient, by the same observer who was unaware of the subject's periodontal status. Statistical analysis was performed using SPSS 11.0 version (SPSS, Inc., Chicago, IL). Mann-Whitney' test was used to compare the PWV (m/s) between two study groups. Spearmen's correlation test was used to determine the correlation between PWV with the plaque index and BOP. Significance level was set at $P<0.05$.

\section{RESULTS}

A total of 17 subjects, 23 to 68 years of age participated in this study. Table 1 shows the demographic and clinical characteristics of the subjects. Owing to the non normal distribution of data, nonparametric analysis of variance on ranks was performed. PWV was higher by $0.5 \mathrm{~m} / \mathrm{sec}$ among subjects with GSCP as compared to those 
Table 1. Demographic and clinical characteristics of subjects

\begin{tabular}{|c|c|c|c|c|}
\hline \multirow{2}{*}{ Variables } & \multicolumn{2}{|c|}{$\begin{array}{l}\text { Localized severe CP } \\
\qquad(n=5)\end{array}$} & \multicolumn{2}{|c|}{$\begin{array}{l}\text { Generalized severe CP } \\
\qquad(n=12)\end{array}$} \\
\hline & Median (IQR) & Frequency (\%) & Median (IQR) & Frequency (\%) \\
\hline Age & $41.0(25.00)$ & & $42.5(8.25)$ & \\
\hline Sex: Male & & $3(60.0)$ & & $4(33.3)$ \\
\hline Female & & $2(40.0)$ & & $8(66.7)$ \\
\hline Smoking status: Yes & & $2(40.0)$ & & $2(16.7)$ \\
\hline No & & $3(60.0)$ & & $10(83.3)$ \\
\hline BMI (kg/m2) & $24.4(3.41)$ & & $24.2(6.05)$ & \\
\hline WHR & $0.84(0.79)$ & & $0.80(0.925)$ & \\
\hline SBP $(\mathrm{mmHg})$ & $120.09(18.00)$ & & $110.0(14.50)$ & \\
\hline $\mathrm{DBP}(\mathrm{mmHg})$ & $74.0(12.00)$ & & $72.0(17.50)$ & \\
\hline PP (mmHg) & $46.0(12.00)$ & & $39.0(9.00)$ & \\
\hline Pulse rate (beat/min) & $68.0(17.00)$ & & $62.0(11.00)$ & \\
\hline Plaque index & $0.50(0.650)$ & & $1.05(0.650)$ & \\
\hline Bleeding in probing (\%) & $32.10(39.950)$ & & $50.05(27.650)$ & \\
\hline
\end{tabular}

Note: $\mathrm{CP}$-Chronic periodontitis; $\mathrm{n}=$ number of subjects; $\mathrm{IQR}=$ interquartile range; $\mathrm{BMI}=$ Body mass index; $\mathrm{WHR}=$ Waist Hip ratio; $\mathrm{SBP}=$ systolic blood pressure; $\mathrm{DBP}=$ diastolic blood pressure, $\mathrm{PP}=$ Pulse pressure.

Table 2. Comparison of PWV between localized severe CP and generalized severe CP subjects

\begin{tabular}{ccccc}
\hline \multirow{2}{*}{ Variable } & $\begin{array}{c}\text { Localized severe CP } \\
(\mathrm{n}=5)\end{array}$ & $\begin{array}{c}\text { Generalized severe CP } \\
(\mathrm{n}=12)\end{array}$ & $\begin{array}{c}\mathrm{Z} \\
\text { Statistics }\end{array}$ & P value $^{\mathrm{a}}$ \\
\cline { 2 - 4 } & Median (IQR) & Median (IQR) & & \\
\hline $\mathrm{PWV}(\mathrm{m} / \mathrm{sec})$ & $7.0(1.50)$ & $7.0(1.03)$ & -1.215 & 0.224 \\
\hline
\end{tabular}

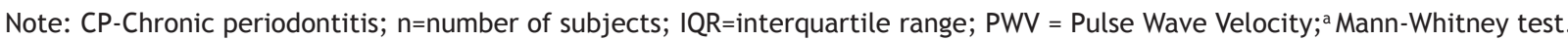

Table 3. Correlation of plaque index and BOP with PWV

\begin{tabular}{lcc}
\hline \multirow{2}{*}{ Variable } & \multicolumn{2}{c}{ PWV (m/sec) } \\
\cline { 2 - 3 } & Correlation coefficient & P value $^{\mathrm{a}}$ \\
\hline Plaque index & -0.223 & NS \\
BOP (\%) & 0.214 & NS \\
\hline
\end{tabular}

PWV=Pulse Wave Velocity; $a$ = Spearman correlation

with LSCP (Tab. 2). There were weak correlation of PWV with plaque index and BOP (Tab. 3).

\section{DISCUSSION}

This study showed that arterial PWV and therefore stiffness is higher in subjects with GSCP as compared to those with LSCP. The difference is $0.5 \mathrm{~m} / \mathrm{sec}$. It means that patients with GSCP have faster $0.5 \mathrm{~m} / \mathrm{sec}$ blood flowing from carotid to femoral compare to LSCP patients. At the beginning, we expected the differences $1 \mathrm{~m} /$ $\mathrm{sec}$ to claim is clinically important; but since only get 17 patients and with that not enough power to achieve it. Increased aortic pulse wave velocity (AoPWV) is an independent predictor of cardiovascular morbidity and mortality. ${ }^{18}$ In the present study, age, sex, smoking status, BMI, waist-hip ratio, SBP and PP did not differ significantly between the two study groups. This is important since aging, hypertension, diabetes mellitus and end stage renal failure influence arterial stiffening. To our knowledge the present study is the first to compare arterial PWV among subjects with severe CP. The relationship between oral health and CVD was investigated by many ${ }^{3,5}$, none compared the extent of periodontal disease with arterial stiffness.

Elter et al. ${ }^{19}$ reported a relationship between the extents of periodontal disease with CVD among subjects with periodontal disease. The Dental ARIC Study in United State showed that the extent of attachment loss ( $\geq 31.4 \%)$ and edentulism was positively associated with incidence of stroke/ 
transient ischemic attack with an odds ratio of $1.3(\mathrm{Cl}, 1.02-1.7)$ and $1.4(1.5-2.0)$ respectively. ${ }^{19}$ They classified the severity of $\mathrm{CP}$ according to the percentage of tooth involved into quartiles, which is similar to our study. On the other hand, Dorfer et al. classified the severity as mean CAL, and found that patients with mean CAL $>6 \mathrm{~mm}$ and gingivitis index $>1.2$ have 7.4 times $(95 \% \mathrm{Cl}=$ 1.70-10.00) and 18.3 times $(95 \% \mathrm{Cl}=5.84-57.26)$ higher risk of developing cerebral ischemia than the controls. ${ }^{20}$ Whereas present study only shown a weak correlation between Plaque index and BOP with the PWV and again maybe due to small number of subjects studied.

Nevertheless, present study indicates a trend of higher arterial stiffness among subjects with GSCP. This relationship may be explained based on hypothetical stimulation of human monocytes and endothelial cells by lipopolysaccharides. Human monocytes and endothelial cells could produce inflammatory substances such as interleukins, TNF-alpha and $\mathrm{C}$ reactive protein. Elevated inflammatorysubstancesmayincreaseinflammatory activity in endothelium, contributing to endothelial dysfunction, arterial stiffness and atherogenesis. With repeated chronic inflammatory events such as in periodontitis, atherosclerotic lesions and thromboembolic events are likely to develop. ${ }^{21}$ Since a strong association of atherosclerosis with arterial stiffness has been shown ${ }^{13}$, a trend of higher PWV among subject with GSCP is explainable and is of clinical interest.

Although the present study shown promising results, but we faced difficulty to find $\mathrm{CP}$ patients free from systemic disease as we known the prevalence of severe $\mathrm{CP}$ in Malaysian population is only $10 \%$ in age range $>40$ years old, this include people who have systemic disease. ${ }^{22}$

Moreover study being cross sectional in nature; it would be difficult to prove whether periodontal findings are partly a sequel rather than a cause of arterial stiffness or a coincidental finding since both the risk factors are quite similar.

\section{CONCLUSION}

This preliminary study showed that aorta is stiffer in GSCP as compared LSCP, although the difference did not reach significant level. CP can also sub classified as moderate and severe, but it remains uncertain whether those with less severe disease would have also higher PWV that would be similar to our study comparative. Future studies with larger sample size, inflammatory markers and periodontal interventions are recommended to prove the relationship between $\mathrm{CP}$, its severity and arterial stiffness conclusively. This study is a part of a parallel group, single blind, randomized clinical trial to evaluate effect periodontal treatment on arterial stiffness which is currently recruiting participants.

\section{ACKNOWLEDEMENTS}

This study was supported by short term grant Universiti Sains Malaysia 304/PPSG/6131484.

\section{REFERENCES}

1. Health MMo. Health facts 2005. Planning and development, information and documentation unit. 2005.

2. Word Health Organization. The World Health Report 2008. Primary health care now more than ever. Word Health Organization. 2008:8.

3. Joshipura KJ, Hung HC, Rimm EB, Willett WC, Ascherio A. Periodontal disease, tooth loss, and incidence of ischemic stroke. Stroke 2003 Jan;34(1):47-52.

4. Stamler J. Research related to risk factors. Circulation 1979 Dec;60(7):1575-87.

5. Mattila KJ, Nieminen MS, Valtonen VV, Rasi VP, Kesaniemi YA, Syrjala SL, et al. Association between dental health and acute myocardial infarction. BMJ 1989Mar25;298(6676):779-81.

6. DeStefano F, Anda RF, Kahn HS, Williamson DF, Russell CM. Dental disease and risk of coronary heart disease and mortality. BMJ 1993Mar13;306(6879):688-91.

7. Wu T, Trevisan M, Genco RJ, Dorn JP, Falkner $\mathrm{KL}$, Sempos CT. Periodontal disease and risk of cerebrovascular disease: The first national health and nutrition examination survey and its follow-up study. Arch Intern Med 20000ct9;160(18):2749-55.

8. Lopez R, Oyarzun M, Naranjo C, Cumsille F, Ortiz M, Baelum V. Coronary heart disease and periodontitis-A case control study in Chilean adults. J Clin Periodontol 2002 May;29(5):468- 
73.

9. Juonala M, Viikari JS, Laitinen T, Marniemi J, Helenius $\mathrm{H}$, Ronnemaa $\mathrm{T}$, et al. Interrelations between brachial endothelial function and carotid intima-media thickness in young adults: the cardiovascular risk in young Finns study. Circulation 2004Nov2;110(18):2918-23.

10. Mercanoglu F, Oflaz $\mathrm{H}, \mathrm{Oz} \mathrm{O}$, Gokbuget AY, GenchellacH, SezerM, etal. Endothelialdysfunction in patients with chronic periodontitis and its improvement after initial periodontal therapy. J Periodontol 2004Dec;75(12):1694-700.

11. Seinost G, Wimmer G, Skerget $M$, Thaller E, Brodmann M, Gasser R, et al. Periodontal treatment improves endothelial dysfunction in patients with severe periodontitis. Am Heart J 2005Jun;149(6):1050-4.

12. Asmar R, Benetos A, Topouchian J, Laurent P, Pannier B, Brisac AM, et al. Assessment of arterial distensibility by automatic pulse wave velocity measurement. Validation and clinical application studies. Hypertension 1995Sep;26(3):485-90.

13. Mattace-Raso FU, van der Cammen TJ, Hofman A, van Popele NM, Bos ML, Schalekamp MA, et al. Arterial stiffness and risk of coronary heart disease and stroke: the Rotterdam Study. Circulation 2006Feb7;113(5):657-63.

14. Silness J, Loe H. Periodontal disease in pregnancy. II: Correlation between oral hygiene and periodontal condition. Acta Odontol Scand1964Feb;22:121-35.

15. Ainamo J, Bay I. Problems and proposals for recording gingivitis and plaque. Int Dent $\mathrm{J}$ 1975Dec;25(4):229-35.

16. Armitage GC. Periodontal diagnoses and classification of periodontal diseases. Periodontol 2000 2004;34:9-21.

17. Tonetti MS, D’Aiuto F, Nibali L, Donald A, Storry C, Parkar M, et al. Treatment of periodontitis and endothelial function. N Engl J Med 2007 Mar1;356(9):911-20.

18. Alecu C, Labat C, Kearney-Schwartz A, Fay R, Salvi $P$, Joly $L$, et al. Reference values of aortic pulse wave velocity in the elderly. J Hypertens 2008Nov;26(11): 2207-12.

19. Elter JR, Offenbacher S, Toole JF, Beck JD. Relationship of periodontal disease and edentulism to stroke/TIA. J Dent Res 2003 Dec;82(12):998-1001.

20. Dorfer CE, Becher H, Ziegler CM, Kaiser C, Lutz $R$, Jorss $D$, et al. The association of gingivitis and periodontitis with ischemic stroke. J Clin Periodontol 2004May;31(5):396-401.

21. Beck JD, Pankow J, Tyroler HA, Offenbacher S. Dental infections and atherosclerosis. Am Heart J 1999Nov;138(5Pt 2):S528-33.

22. Oral Health Division MoHM. National oral health survey of adults 2000 (NOHSA 2000). 2004:36-43. 